\title{
Branchial Cysts in Quito, Ecuador
}

\author{
Luis Pacheco-Ojeda10 Andrés Ayala-Ochoa ${ }^{2}$ Karla Salvador ${ }^{3}$ \\ ${ }^{1}$ Department of Surgery, Centro Médico Oncológico, Quito, \\ Pichincha, Ecuador \\ 2 Department of Surgery, Hospital Vozandes Quito, Quito, \\ Pichincha, Ecuador \\ ${ }^{3}$ Department of Otorhinolaryngology, Hospital de Ninos Baca Ortiz, \\ Quito, Pichincha, Ecuador
}

Int Arch Otorhinolaryngol 2020;24(3):e347-e350.

\begin{abstract}
Address for correspondence Luis Pacheco-Ojeda, MD, Departamento de Cirurgia, Centro Médico Oncológico, Av. América 18-02, Quito 170150, Ecuador (e-mail: luispacheco.o@hotmail.com).
\end{abstract}

\begin{abstract}
Keywords

- branchial cysts

- neck

- surgical

Introduction Branchial cleft anomalies are the second most common congenital anomaly in children. However, some lesions may not develop clinically and are not diagnosed until adulthood. The recent literature of branchial cysts (BCs) in the adult population is really scanty. For this reason, we analyzed the clinical and surgical management of the adult population treated for a BC at a tertiary care general hospital. Methods A retrospective review of the clinical records of all the patients with histological diagnosis of BC who were surgically treated at the Social Security Hospital in Quito, Ecuador, was performed. Fifty-one patients (27 women) with congenital anomalies of the $2^{\text {nd }}$ ( 43 patients with cysts) and $3^{\text {rd }}$ ( 6 patients with cysts and 2 with fistula) branchial arches were diagnosed and treated. Diagnosis was made on clinical grounds and by computed tomography scan.

Results The 43 patients with a $2^{\text {nd }}$ branchial cleft cyst underwent complete surgical excision through a wide mid-neck transverse cervicotomy. The 6 cases of $3^{\text {rd }}$ branchial cleft cyst underwent surgical resection through a lower-neck transverse incision, and the 2 patients with clinical fistula in the lower aspect of the neck were operated on via an elliptical incision around this external fistula opening. Postoperative evolution was uneventful in all patients.

Conclusions Branchial cysts can occasionally be diagnosed in adult patients in the setting of a general hospital population. A correct clinical and imaging assessment was diagnostic in most patients. Complete surgical resection was curative in all our patients, and postoperative complications were exceptional.
\end{abstract}

\section{Introduction}

Branchial anomalies comprise $\sim 20 \%$ of pediatric congenital head and neck masses, making them the second most common, preceded only by thyroglossal duct cysts,. ${ }^{1}$ Conversely, they are uncommon in adults. Although the term branchial anomaly encompasses first, second, third, and fourth branchial cleft cysts, sinuses, and fistulae, all are thought to result from a similar embryologic error: incomplete obliteration of the branchial apparatus during embryogenesis. ${ }^{2}$

received

February 21, 2018

accepted

June 20, 2019

published online

January 9, 2020
DOI https://doi.org/ 10.1055/s-0039-1695023. ISSN 1809-9777.
Three different clinical presentations are recognized: cysts, sinuses, and fistulae. ${ }^{3}$ When a pouch or groove fails to obliterate, it may communicate with either skin or mucosa of the upper airway, forming a sinus. When both a pouch and a groove fail to obliterate, they may form a communication between the skin and mucosa, which is termed a fistula. When a branchial groove remnant forms an epithelial-lined space without communication to the skin or mucosa, a cyst is formed. ${ }^{1}$ Cystic neck lumps are a diagnostic challenge for the head and neck

Copyright $\odot 2020$ by Thieme Revinter Publicações Ltda, Rio de Janeiro, Brazil
License terms

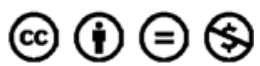




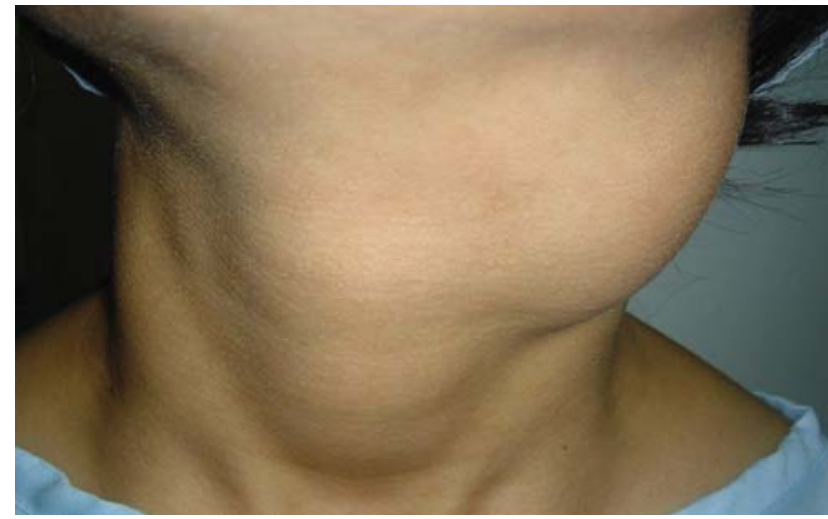

Fig. 1 A left branchial cyst.

surgeon. ${ }^{4}$ Preoperative differential diagnoses include thyroglossal duct cyst, cervical lymphadenitis, cervical abscess, toxoplasmosis, tuberculosis, dermoid, dermal inclusion cyst, hydatid cyst, lymphangioma, and malignant neoplasm.,6

The recent literature of branchial cysts (BCs) in the adult population is really scanty. For this reason, we analyzed the clinical and surgical management of patients in this age group treated for a BC at a tertiary care general hospital.

\section{Methods}

A retrospective review of the clinical records of all the patients with histological diagnosis of $\mathrm{BC}$ who were surgically treated between 1990 and 2015 at the department of otolaryngology head and neck surgery of the Social Security Hospital in Quito, Ecuador, South America. Was performed during this period, 51 patients (24 men, 27 women) with congenital anomalies of the $2^{\text {nd }}$ (43 patients with cysts) and $3^{\text {rd }}(6$ patients with cysts, and 2 with fistula) branchial arches were diagnosed and treated. The mean age of the patients was 31 (range 4-60). Forty-eight patients (94\%) were adults, and only 3 were under 18 -years old. The preoperative diagnosis was based on history, clinical examination, and radiology reports. Forty-nine patients (96\%) presented with lateral neck soft swelling; among them, 43 ( - Fig. 1) were located cranially and only 6 in the lower neck (levels IV and VB). Two patients presented with fistulae in the lower neck. Symptoms appear on - Table 1; lesions were asymptomatic in 47 (92\%) patients. The mean length of time from onset of tumor or symptoms was 13.8 months. Clinical

Table 1 Symptoms in patients with branchial cysts

\begin{tabular}{|l|l|}
\hline Symptoms & Number of cases \\
\hline Local pain & 6 \\
\hline Fistula drainage & 2 \\
\hline Dysphagia & 2 \\
\hline Local burning & 1 \\
\hline Fever & 1 \\
\hline None & 47 \\
\hline
\end{tabular}

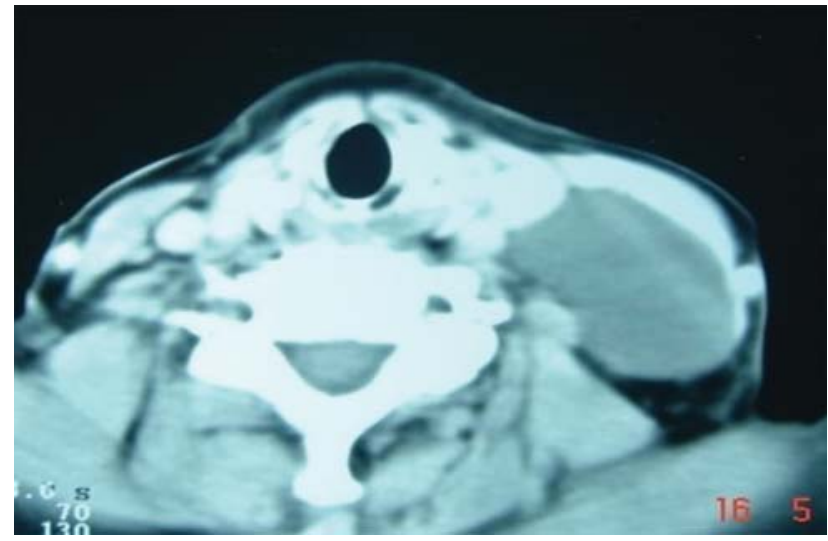

Fig. 2 Computed tomography scan showing a characteristic image of a branchial cyst.

diagnosis was BC in 42 cases (82\%), inflamed BC in $4(8 \%)$, branchial fistula in 2, malignant lymph node in 2 , and cystic hygroma in 1 case. Twenty-eight lesions (55\%) were located on the left side, 22 on the right side and 1 medially, above the sternal notch.

Fine needle aspiration (FNA) biopsy was performed in 18 patients (35\%) with cystic lesions. It was diagnostic in 15 cases (83\%).

Among the imaging studies performed, ultrasound (US) report was correct in 7 (76\%) of 26 patients, computed tomography (CT) report in 20 (95\%) (-Fig. 2) of 21, and magnetic resonance imaging (MRI) report in all 4 patients in whom these studies were performed. Fistulography was performed in the two patients with lower neck fistula.

\section{Results}

The 43 patients with a $2^{\text {nd }}$ branchial cleft cyst underwent complete surgical excision through a wide mid-neck transverse cervicotomy incision under general anesthesia with orotracheal intubation. These lesions were located superficial to the anterior border of the sternocleidomastoid muscle or adjacent to the carotid sheath ( - Fig. 3 ). We did not have any case of cyst located through the carotid bifurcation or deep into the carotid sheath. A lower neck transverse incision was the

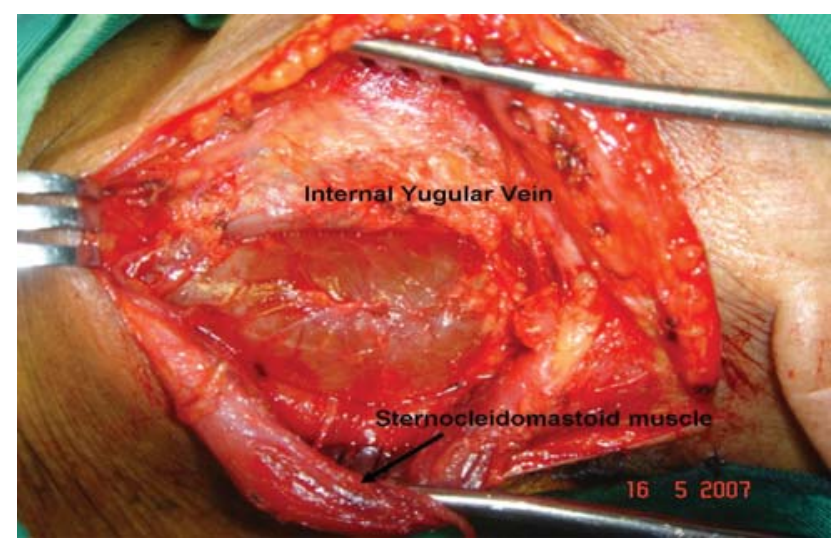

Fig. 3 Surgical view of the second arch branchial cyst. 
approach used to operate on the 6 patients with $3^{\text {rd }}$ branchial cleft cyst. The two patients with clinical fistula in the lower aspect of the neck were operated on via an elliptical incision around this external fistula opening. The tract was injected with methylene blue; the fistula extended through the carotid bifurcation up to the pharyngeal constrictor muscles, and it was completely resected. An aspiration drain was left in place for 48 hours. Prophylactic antibiotic was given for 24 hours to all patients, with the exception of the 4 patients with clinical diagnosis of abscessed branchial cyst to whom a complete antibiotic treatment was given.

Postoperative evolution was uneventful in all patients. One patient developed a mild fibrosis under the scar. Histological study of all the lesions reported a characteristic BC. No recurrences occurred during a mean follow-up of 7 (range $0.3-18)$ years.

\section{Discussion}

In 1832, Ascherson described the first BC and suggested that this resulted from the impaired obliteration of the branchial cleft or pouches. ${ }^{7}$

Branchial cleft anomalies are the second most common congenital anomaly in children. ${ }^{8}$ However, some lesions may not develop clinically and are not diagnosed until adulthood. The recent literature of BCs in the adult population is really scanty, and we found only one review ${ }^{9}$ and some case reports. ${ }^{10-12}$ The majority of cases in adults arise between the ages of 20 and 40 years old, but ${ }^{11}$ in older patients branchial cleft cysts are a diagnostic challenge because of the possibility of cystic metastasis from occult squamous cell or papillary thyroid carcinoma. $4,13,14$

As our study was made with patients from a tertiary general hospital, most of them (92\%) were adults. The mean age in our series is similar to the 32 years reported by Guldfred. ${ }^{4}$

Among $1132^{\text {nd }}$ arch BCs reported by Agaton-Bonilla, ${ }^{15}$ $76 \%$ were located on the left side, but among the 62 cases of second branchial cleft anomalies reported by Bajaj, ${ }^{2} 34$ were located on right side and 12 were bilateral. We had left side predominance but no case of bilateral lesions.

Gender distribution seems similar for both males and females. ${ }^{2,8}$ However, a few authors have reported higher incidence in either men or women. ${ }^{5,15-19}$ We found slightly more females than males in our series.

Branchial cysts are often lined with squamous epithelium, whereas sinuses and fistulae are more likely to be lined with ciliated, columnar epithelium. ${ }^{20}$ Lymphoid tissue, sebaceous glands, salivary tissue or cholesterol crystals in mucoid fluid within the cysts can be seen. Squamous cell carcinoma within the cyst can be found in adults, but it seems to be extremely difficult to differentiate a primary lesion from a metastatic lesion from an occult primary. ${ }^{21,22}$

Second arch BCs appear clinically as a solitary, painless, lateral swelling in the upper neck, ${ }^{1,23}$ while third and fourth anomalies are found lower in the neck. ${ }^{8}$

They appeared inflamed in $10 \%$ of cases, ${ }^{4}$ which is similar to our $8 \%$ rate. However, rates ranging from 23 to $35 \%$ have been reported. ${ }^{18,19,24}$ When the cysts are infected, a history of intermittent swelling and tenderness is present, such as sore throat, upper respiratory tract infection, or dental infection.

Branchial cleft diagnosis depends on good history taking and examination as well as a high index of clinical suspicion. ${ }^{2}$ In patients with cysts, US is the first reliable imaging technique, but CT and MRI are useful to confirm the diagnosis and define the extent of the lesion. ${ }^{2}$ When infected, the cyst wall or tract tends to become thickened and irregular, and it is enhanced with intravenous contrast. Magnetic resonance imaging has an excellent soft tissue detail. ${ }^{22}$ In Schroeder's study $^{16}$ of 74 branchial anomalies in children, including 22 cysts, these cysts were accurately diagnosed in $95 \%$ of cases using CT scan. This was similar in our patients in whom CT scan was used. In this mentioned series, preoperative diagnosis of BC was accurate in $95 \%$ of cases; almost the same as the $94 \%$ rate in our series. In adults, it is very important to rule out the possibility of the presence of a metastatic lymph node, particularly squamous cell carcinoma of the tonsil or papillary thyroid cancer, which may mimic a $\mathrm{BC} .{ }^{4}$ In case of fistulae, contrast study, and, eventually, CT can help in defining the location and extent of the tract. ${ }^{2,22,25}$

The second arch forms the hyoid bone and adjacent areas of the neck. This could explain the case of a lesion close to the hyoid bone and initially diagnosed as a thyroglossal cyst. The second BCs and sinuses are lateral along the anterior border of the sternocleidomastoid muscle in the mid neck. They are classified into 4 types according to their anatomic relationship to the carotid vessels. All of our cases lied anterior to the sternocleidomastoid muscle (type I) or deep into this muscle but lateral to the carotid sheath (type II).

Fine needle aspiration biopsy has been performed in $35^{8}$ to $100 \%{ }^{4}$ of cystic lesions, and it has been diagnostic in $86 \%{ }^{15}$ Epithelial and polymorphonuclear cells as well as macrophages have been commonly found in aspirates. In Guldfred's series, ${ }^{4}$ among the patients who ultimately were diagnosed of malignancy, no signs of malignancy were seen on cytological examination.

Preoperative incision and drainage can be required in some patients with inflamed cysts. ${ }^{4}$ Our 4 patients with inflamed cyst were treated with antibiotics preoperatively and did not need this surgical procedure.

Based on proper diagnostic workup, a correct diagnosis will lead to proper surgical management ${ }^{23}$ because branchial cleft cysts and sinuses are better managed with surgical resection. Dissection must carefully include the entire tract. Detailed knowledge of the vascular anatomy and surrounding nerves is necessary for safe and complete resection. ${ }^{8}$

Complications were unusual in Bajaj's series; ${ }^{2}$ there was only one seroma, similar to our series. However, wound infection and bleeding can occur in 6 to $9 \%$ of cases. ${ }^{4,15}$ Nerve injuries, involving the spinal accessory nerve, the great auricular nerve, the hypoglossal nerve, the mandibular branch of the facial nerve, and the superior laryngeal nerve have also been reported. ${ }^{4,15}$ Shroeder ${ }^{16}$ reported 8 minor and 9 major complications in his study of 74 cases.

The reported recurrence rate after primary excision ranges between 3 and 7\%, 2,15,16 and it is less common for $2^{\text {nd }}$ branchial cleft lesions. Fortunately, we did not have any 
recurrence in our series. Our patients belonged to the National Ecuadorian Social Security System in which follow up is free and they could be attended whenever they needed.

Complete (58-61\%) or partial (25-70\%) regressions of BC have been obtained with sclerotherapy using OK-432 injections, with greater success in unilocular cysts when compared with multilocular. $^{26,27}$

\section{Conclusions}

Branchial cysts can occasionally be diagnosed in adult patients in the setting of a general hospital population. Complete surgical resection was curative in all our patients, and postoperative complications were uncommon.

Conflict of Interests

The authors have no conflict of interests to declare.

\section{References}

1 Goff CJ, Allred C, Glade RS. Current management of congenital branchial cleft cysts, sinuses, and fistulae. Curr Opin Otolaryngol Head Neck Surg 2012;20(06):533-539. Doi: 10.1097/MOO.0b013e 32835873fb

2 Bajaj Y, Tweedie D, Ifeacho S, Hewitt R, Hartley BE. Surgical technique for excision of first branchial cleft anomalies: how we do it. Clin Otolaryngol 2011;36(04):371-374. Doi: 10.1111/j.17494486.2011.02312.x

3 Glosser JW, Pires CA, Feinberg SE. Branchial cleft or cervical lymphoepithelial cysts: etiology and management. J Am Dent Assoc 2003;134(01):81-86

4 Guldfred LA, Philipsen BB, Siim C. Branchial cleft anomalies: accuracy of pre-operative diagnosis, clinical presentation and management. J Laryngol Otol 2012;126(06):598-604. Doi: 10.1017/S00 22215112000473

5 Kenealy JF, Torsiglieri AJ Jr, Tom LW. Branchial cleft anomalies: a five-year retrospective review. Trans Pa Acad Ophthalmol Otolaryngol 1990;42:1022-1025

6 Daoud FS. Branchial cyst: an often forgotten diagnosis. Asian J Surg 2005;28(03):174-178

7 Golledge J, Ellis H. The aetiology of lateral cervical (branchial) cysts: past and present theories. J Laryngol Otol 1994;108(08):653-659

8 Cabrini A. LaRiviere, MD, MPH, John H.T. Waldhausen, MD. Congenital Cervical Cysts, Sinuses, and Fistulae in Pediatric Surgery. Surg Clin North Am 2012;92:583-597. Doi: 10.1016/j. suc.2012.03.015
9 Ballivet de Régloix S, Maurin O, Crambert A, Genestier L, Bonfort G, Pons Y. Kystes et fistules congenitaux du cou chez l'adulte. Presse Med 2018;pii:S0755-4982 (18)30376-2.

10 Erickson LA. Branchial Cleft Cyst in Lateral Neck of an Adult. Mayo Clin Proc 2017;92(04):e69-e70

11 Muller S, Aiken A, Magliocca K, Chen AY. Second Branchial Cleft Cyst. Head Neck Pathol 2015;9(03):379-383

12 Brea-Álvarez B, Roldán-Hidalgo A. [Cysts in the posterior triangle of the neck in adults]. Acta Otorrinolaringol Esp 2015;66(02):106-110

13 Gourin CG, Johnson JT. Incidence of unsuspected metastases in lateral cervical cysts. Laryngoscope 2000;110(10 Pt 1):1637-1641

14 Sharma SD, Stimpson P. Assessment and management of presumed branchial cleft cysts: our experience. B-ENT 2016;12(04): 291-296

15 Agaton-Bonilla FC, Gay-Escoda C. Diagnosis and treatment of branchial cleft cysts and fistulae. A retrospective study of 183 patients. Int J Oral Maxillofac Surg 1996;25(06):449-452

16 Schroeder JW Jr, Mohyuddin N, Maddalozzo J. Branchial anomalies in the pediatric population. Otolaryngol Head Neck Surg 2007;137(02):289-295. Doi: 10.1016/j.otohns.2007.03.009

17 Titchener GW, Allison RS. Lateral cervical cysts: a review of 42 cases. N Z Med J 1989;102(877):536-537

18 Kadhim AL, Sheahan P, Colreavy MP, Timon CV. Pearls and pitfalls in the management of branchial cyst. J Laryngol Otol 2004;118 (12):946-950

19 Deane SA, Telander RL. Surgery for thyroglossal duct and branchial cleft anomalies. Am J Surg 1978;136(03):348-353

20 Waldhausen $\mathrm{JH}$. Branchial cleft and arch anomalies in children. Semin Pediatr Surg 2006;15(02):64-69. Doi: 10.1053/j.semped surg.2006.02.002

21 Roback SA, Telander RL. Thyroglossal duct cysts and branchial cleft anomalies. Semin Pediatr Surg 1994;3(03):142-146

22 Prosser JD, Myer CM III. Branchial cleft anomalies and thymic cysts. Otolaryngol Clin North Am 2015;48(01):1-14

23 Zaifullah S, Yunus MR, See GB. Diagnosis and treatment of branchial cleft anomalies in UKMMC: a 10-year retrospective study. Eur Arch Otorhinolaryngol 2013;270(04):1501-1506. Doi: 10.1007/s00405-012-2200-7

24 Fleming WB. Infection in branchial cysts. Aust N Z J Surg 1988;58 (06):481-483

25 Work WP, Proctor CA. The otologist and first branchial cleft anomalies. Ann Otol Rhinol Laryngol 1963;72:548-562. Doi: 10.1177/ 000348946307200221

26 Roh JL, Sung MW, Hyun Kim K, Il Park C. Treatment of branchial cleft cyst with intracystic injection of OK-432. Acta Otolaryngol 2006;126(05):510-514

27 Kim MG, Lee NH, Ban JH, Lee KC, Jin SM, Lee SH. Sclerotherapy of branchial cleft cysts using OK-432. Otolaryngol Head Neck Surg 2009;141(03):329-334 